\title{
Effects of EMG-Biofeedback Using Closed Kinetic Chain Exercise on Q-angle and Quadriceps Muscle Activation in Patellofemoral Pain Syndrome
}

Je-Ho Kim

Department of Physical Therapy, Graduate School, Sehan University

Purpose: The aim of this study was to determine the effects of electromyographic (EMG)-Biofeedback using closed kinetic chain exercise (EB-CKCE) on quadriceps angle ( $\mathrm{Q}$-angle) and quadriceps muscle activation and muscle activation ratio in subjects with patellofemoral pain syndrome and to provide fundamental information on rehabilitation exercise in patellofemoral pain syndrome.

Methods: Thirty participants who met the criteria were included. The subjects were randomly divided into three groups: control group (Group I, $n=10$ ), semi-squat exercise group (Group II, $n=10$ ), and EMG-Biofeedback using closed kinetic chain exercise group (Group III, $n=10$ ). Intervention was provided to each group for eight weeks (three times per week; 30 minutes per day). Subjects were measured on Q-angle and quadriceps muscle activation.

Results: Significant difference in Q-angle and quadriceps muscle activation was observed in groups II and III compared with control group I ( $p<0.01$ ). Results of post-hoc analysis showed a significant difference in 0 -angle and quadriceps muscle activation in on group III compared with groups I and II.

Conclusion: Findings of this study suggest that closed kinetic chain exercise using EMG-Biofeedback that provides real-time biofeedback information on muscle contraction may have a beneficial effect on improvement of $\mathrm{Q}$-angle and quadriceps muscle activation in patellofemoral pain syndrome.

Keywords: Patellofemoral pain syndrome, Q-angle, Quadriceps muscle activation, EMG-Biofeedback

\section{서 론}

무릎넙다리통증증후군(patellofemoral pain syndrome, PFPS)은 무릎 통증의 가장 빈번한 형태로, 무릎뼈의 앞쪽 또는 뒤쪽에서 통증이 나 타나고 지속적인 앉기, 계단 오르내리기, 무릎꼻기 등의 활동에서 통 증이 악화되며 활동성이 많은 젊은 여성에게 유병률이 높다고 하였 다.1,2 PFPS의 병태생리학적인 원인은 명확하지는 않지만, 다리근육의 짧아짐과 다리근력의 불균형, 증가된 넙다리네갈래근 각(quadriceps angle, Q-각) 등에 의한 무릎관절의 과도한 스트레스는 무릎뼈의 비 정상적인 움직임과 부정렬(Malalignment)을 유발한다. ${ }^{3}$ 그 중 안쪽빗 넓은근(vastus medialis oblique, $\mathrm{VMO}$ )의 약화는 무릎뼈의 가쪽당김 을 야기하고 Q-각을 증가시켜 넙다리네갈래근과 무릎힘줄 사이에 벡터 합성에서 더 큰 가쪽활시위(lateral bowstringing) 힘을 생산하기
때문에 관절면에 대한 스트레스를 증가시킨다. ${ }^{4,5}$ Freedman 등 ${ }^{6}$ 은 $\mathrm{PFPS}$ 를 보이는 43 명을 대상으로 $\mathrm{Q}$-각과 무릎관절의 운동형상학적 변인의 상관관계연구에서 Q-각과 무릎뼈의 가쪽탈구는 양의 상관 관계를 보였으며, 넙다리네갈래근 근력과는 음의 상관관계를 보였다. Miao 등근 PFPS를 보이는 30명을 대상으로 가쪽넓은근과 안쪽빗넓 은근의 근활성도의 비율(ratio)를 비교한 결과 건강한 성인은 약 1:1이 지만 PFPS를 보이는 대상자는 가쪽넓은근이 안쪽빗넓은근과 비교 하여 높게 활성화 되었다. PFPS는 가쪽넓은근과 안쪽빗넓은근 사이 의 근활성도에 불균형에 의해 유발되기 때문에 무릎뼈의 정상적인 움직임과 올바른 정렬을 위해서는 안쪽빗넓은근의 강화가 필요하다 고 하였다. ${ }^{89}$

PFPS의 치료를 위한 중재방법으로 넙다리네갈래근의 근력강화운 동이 보편적으로 중재되고 있으며 운동수행의 행태는 열린 운동학 
적사슬 운동(open kinetic chain exercise, OKCE)과 닫힌 운동학적사슬 운동(close kinetic chain exercise, $\mathrm{CKCE}$ )으로 나누어진다. ${ }^{10} \mathrm{CKCE}$ 는 근 육의 동원(recruitment) 시 동시-활성(co-activation)을 통하여 관절에 안정성을 제공하고 고유수용성 감각의 입력을 증가시키며, $\mathrm{OKCE}$ 는 견인력과 회전력을 증가시키고 외적 부하를 통해 안정성을 제공하여 균형능력 및 보행능력을 향상시킨다. ${ }^{11,12}$ Irish 등'3은 OKCE와 CKCE 를 비교한 연구에서 $\mathrm{CKCE}$ 에서는 가쪽넓은근에 대한 안쪽빗넓은근 의 근활성 비율이 증가하였지만, $\mathrm{OKCE}$ 에서는 안쪽빗넓은근의 근활 성 비율의 증가를 보이지 않아 안쪽빗넓은근의 근력강화가 필요한 PFPS는 반웅크리기(semi-squat) 운동과 같은 CKCE가 OKCE와 비교 하여 더 효과적인 중재방법이라고 하였다.

근전도-생체되먹임(EMG-Biofeedback, EB) 훈련은 움직임을 수행 하는 동안 운동단위의 활동전위에 관한 정보를 제공함으로써 근육 뼈대계 질환 및 신경계 질환 등 다양한 질환의 재활훈련 과정에 이용 되며, 통증감소와 근력 및 기능수행력을 향상시키는 데 효과적인 방 법이다. ${ }^{14-16}$ Oravitan과 $\mathrm{Avram}^{17}$ 은 반월판 재건술 환자를 대상으로 근 전도-생체되먹임 훈련을 통한 가쪽넓은근과 안쪽넓은근의 선택적 근력강화로 근력과 기능수행력 평가에서 유의한 향상을 보였고, $\operatorname{Kim}$ 등 18 은 무릎뼈 부정렬 환자를 대상으로 근전도-생체되먹임 훈련 을 통한 안쪽빗넓은근의 선택적 근력강화로 근력의 향상과 통증의 감소를 보고하였다.

닫힌 운동학적사슬 운동을 이용한 다리 근력강화가 PFPS를 보이 는 대상자의 통증 및 근력향상에 관한 연구는 현재 활발하게 이루어 지고 있으며, 근전도-생체되먹임을 이용한 중재 또한 다양한 질환에 서 연구가 이루어지고 있다. 하지만 PFPS와 같이 선택적인 안쪽빗넓 은근의 근력강화가 필요한 환자에게 근전도-생체되먹임을 이용한 닫 힌 운동학적사슬 운동을 중재한 연구는 미흡한 실정이다. 따라서 본 연구에 목적은 PFPS를 보이는 대상자에게 근전도-생체되먹임을 이 용한 닫힌 운동학적사슬 운동이 Q-각과 넙다리네갈래근의 근활성 도에 미치는 영향을 알아보고 PFPS의 재활운동에 기초자료를 제공 하고자 한다.

\section{연구방법}

\section{1. 연구대상}

본 연구는 전남 소재의 대학교에 재학중인 여자대학생 중 본 연구의 목적과 실험방법에 대하여 충분한 설명을 듣고 자발적으로 참여하 기로 동의한 대상자에서 사전 설문을 통해 Kujala Patellofemoral Score 에서 70점 이상 80 점 미만의 무릎넙다리관절에 기능부전을 가지고 있는 대상자 30 명을 선정하였다. 본 연구의 세부적인 선정기준은 무 릎관절을 포함한 그 외 다리관절에 정형외과적 수술을 받지 않은 자, 최근 1 개월 안에 다리근력강화 운동을 하지 않은 자, 기타 다른 내·외 과적 의학적 질환을 가지고 있지 않은 자로 선정하였다(Table 1).

\section{2. 실험방법}

본 연구는 총 30 명의 연구대상자를 무작위 임의 선정하여 각각 10 명 씩 대조군(Group I), 반웅크리기 운동군(Group II), 근전도-생체되먹 임을 이용한 닫힌 운동학적사슬 운동군(Group II)으로 나누어 중재 하였다.

\section{1) 반웅크리기 운동}

반웅크리기 운동의 자세는 양 발은 어깨넓이만큼 벌린 후 중립위치 를 유지하였고 몸통은 곧게 편 자세(upright position)를 취하였으며 어 깨는 $90^{\circ}$ 굽힘하였다. ${ }^{19}$ 웅크리기 운동 중 40-60 범위에서 무릎관절 을 굽힘하는 반웅크리기 운동을 시행하였으며, 본 연구에서는 $45^{\circ}$ 굽 힘 후 6 초간 반웅크리기 자세를 유지한 후 다시 초기 자세로 되돌아 왔으며 이완은 10 초 동안 하였다. 운동의 수행은 2 분 동안 수축 (squeeze)-수축(squeeze)-이완(relax)의 3가지 절차로 수행하였고 운동 과 운동 사이에는 4 분의 휴식시간이 제공되었다. 운동은 8 주 동안 주3회, 1 일 30 분씩 중재하였다.

\section{2) 근전도-생체되먹임을 이용한 닫힌 운동학적사슬 운동}

중재자세와 시간은 반웅크리기 운동과 동일하며 안쪽빗넓은근의 선 택적인 근력강화를 위해 근수축에 대한 정보를 실시간으로 제공하

Table 1. General characteristics of subjects

\begin{tabular}{lccr}
\hline & Group I $(\mathrm{n}=10)$ & Group II $(\mathrm{n}=10)$ & Group III $(\mathrm{n}=10)$ \\
\hline Age (year) & $21.55 \pm 1.32$ & $21.60 \pm 1.46$ & $22.02 \pm 1.31$ \\
Height $(\mathrm{cm})$ & $160.11 \pm 5.45$ & $159.94 \pm 5.81$ & $161.01 \pm 5.74$ \\
Weight $(\mathrm{kg})$ & $52.61 \pm 2.64$ & $51.91 \pm 2.82$ & $52.11 \pm 3.04$ \\
KPS (score) & $75.28 \pm 4.31$ & $76.12 \pm 3.52$ & $75.90 \pm 4.08$ \\
\hline
\end{tabular}

Values are present as mean \pm standard deviation.

Group I: control group.

Group II : semi-squat exercise group.

Group III: EMG-Biofeedback using closed kinetic chain exercise group.

KPS: Kujala patellofemoral score. 
는 E-LINK system (Biometric Inc, United Kingdom)의 Myo-Ex를 이용 하였다. ${ }^{20} \mathrm{E}-\mathrm{LINK}$ system의 Myo-Ex는 피부에 부착된 전극을 통해 근 활성의 정도를 모니터를 통해 제공하고 바나나 따는 원숭이(monkeys activity modules), 스키활강 게임(Downhill activity modules) 등의 과제 지향적 훈련프로그램을 통해 운동학습과 운동조절에 효과적이다 (Figure 1).

\section{3. 측정방법}

1) $Q-$ 각 측정

반웅크리기 운동을 하는 동안 Q-각의 측정은 LUKOtronic (Lutz-Kovacs Electronic, Austria) 동작분석시스템을 이용하였다. 구성요소는 동작분 석을 위한 카메라, 적외선 마커, 분석용 소프트웨어가 내장된 개인용 컴퓨터로 구성되어 있으며, 수집된 데이터는 AS202를 이용하여 분석 하였다(Figure 2A). Q-각은 무릎관절 굽힘 $45^{\circ}$ 의 반웅크리기 자세에서 측정하였으며 위앞엉덩뼈가시와 무릎뼈의 중심을 잇는 선과 무릎뼈 의 중심과 정강뼈거친면을 잇는 선 사이의 각도를 계산하였고 마커는 위앞엉덩뼈가시, 무릎빼, 정강뼈거친면에 부착하였다(Figure 2C). ${ }^{21}$

\section{2) 표면근전도시스템}

다리 근활성도를 측정하기 위해 MP100 표면근전도 시스템(Biopac System Inc, USA)을 이용하였고, 디지털 신호로 변환된 자료는 개인용 컴퓨터에서 Acqknowledge 3.91 소프트웨어를 이용하여 자료 처리하 였다. 표면근전도 신호에 대한 피부저항을 최소화하기 위해 부착부 위의 털을 제거하고 가는 사포로 3-4회 문질러 피부각질층을 제거한 후, 소독용 알코올 솜으로 피부를 깨끗이 하였다. 부착 근육은 가쪽 넓은근, 안쪽빗넓은근에 부착하였고 이극전극은 각 근육의 근힘살 (muscle belly)에 근섬유의 방향과 평행하게 부착하였다. 안쪽빗넓은 근의 전극은 무릎벼의 위안쪽 가장자리(supromeidal patellar border) 에서 위쪽 $4 \mathrm{~cm}$, 안쪽 $4 \mathrm{~cm}$, 무릎뼈 긴축(long axis)에서 $55^{\circ}$ 위치에 부 착하였고, 가쪽넓은근의 전극은 무릎뼈의 위안쪽 가장자리에서 위 쪽 $10 \mathrm{~cm}$, 가쪽 6-8 cm, 무릎뼈 긴축에서 $15^{\circ}$ 위치에 부착하였다(Figure 2C). 표본추출률(sampling rate)은 $1,024 \mathrm{~Hz}$ 로 설정하였고, 잡음을 최소화하기 위해 대역 여과 필터(notch filter)는 $60 \mathrm{~Hz}$, 대역 통과 필터 (band pass filter) 30-450 Hz로 설정하였으며 수집된 신호는 RMS 처리 하였다(Figure 2B).

\section{3) 근활성도의 표준화}

근활성도의 표준화(normalization)를 위해 \%최대 수의적 수축 (\%maximal voluntary contraction, \%MVC)을 이용하였다. 무릎관절 $45^{\circ}$ 굽힘 시 5 초 동안 최대 수의적 등척성 수축(maximal voluntary isometric contraction)의 근활성도를 산출한 후 반웅크리기 운동을 하는

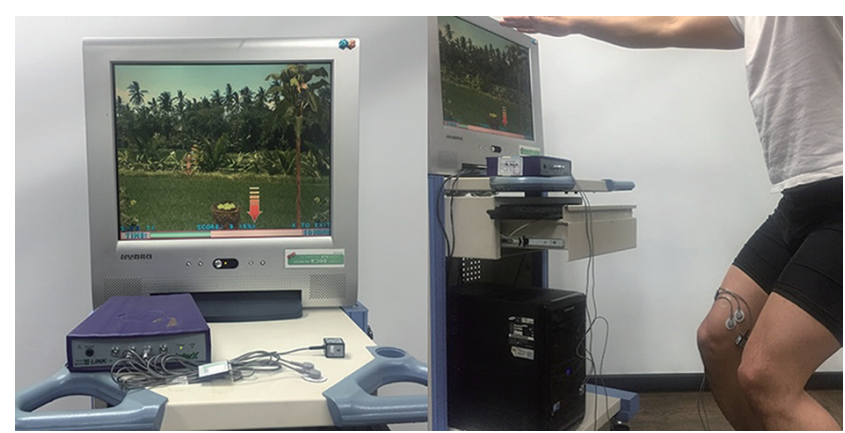

Figure 1. E-LINK system: Myo-Ex.
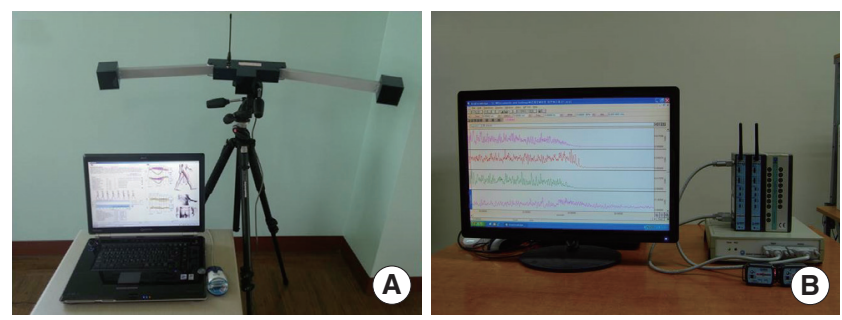

Figure 2. (A). Motion capture system, (B). sEMG.

동안 산출된 가쪽넓은근과 안쪽빗넓은근의 근활성도의 값과 비교 하여 $\% \mathrm{MVC}$ 값을 산출하였다. 모든 근활성도는 5 초의 신호 중 처음 과 마지막 1 초씩을 제외한 3 초의 신호를 이용하였으며, 3 회 측정된 평 균값을 이용하였다. ${ }^{13}$

\section{4) 안쪽빗넓은근/가쪽넓은근의 근활성비(muscle activation ratio)} 반웅크리기 운동 시 측정된 안쪽빗넓은근과 가쪽넓은근의 RMS 값 을 서로 나누어 비율을 산출하였다. ${ }^{13}$

\section{4. 분석방법}

본 연구에서 측정된 자료는 SPSS ver. 19.0 for Window (IBM Co., Armonk, NY, USA)을 이용하여 통계처리 하였다. 그룹 간 정규성 검정을 위해 Shaphiro-wilk 검정을 실시하였고, 그룹 간 중재 전·후 Q-각과 넙 다리네갈래근의 근활성도의 차이를 검증하기 위해 공분산분석(ANCOVA)을 이용하여 분석하였으며 사후검정은 Bonferroni 검정을 실 시하였다. 통계학적 유의수준은 $\alpha=0.05$ 로 하였다.

\section{결 과}

\section{1. 그룹 간 Q-각 비교}

그룹 간 중재 전. 후 Q-각의 비교 결과, 그룹 $\mathbb{I}$ 와 그룹 $\mathbb{I I}$ 은 그룹 I 과 비교하여 $\mathrm{Q}-$ 각에 유의한 차이를 보였다 $(\mathrm{p}<0.05)$. 사후검정 결과 그 룹 III은 그룹 I, II와비교하여 Q-각의 감소에 효과적이었다(Table 2). 
Table 2. Comparison of Q-angle and quadriceps muscle activation between groups

\begin{tabular}{|c|c|c|c|c|c|c|c|c|c|}
\hline & \multicolumn{2}{|c|}{ Group I $(n=10)$} & \multicolumn{2}{|c|}{ Group II $(n=10)$} & \multicolumn{2}{|c|}{ Group III $(n=10)$} & \multirow{2}{*}{$\mathrm{F}$} & \multirow{2}{*}{$\mathrm{t}$} & \multirow{2}{*}{ post-hoc } \\
\hline & pre & post & pre & post & pre & post & & & \\
\hline Q-angle (unit: ${ }^{\circ}$ ) & $23.35 \pm 3.27$ & $23.31 \pm 3.31$ & $23.42 \pm 3.41$ & $22.73 \pm 2.94$ & $23.37 \pm 3.39$ & $22.40 \pm 3.08$ & 3.245 & $0.047^{*}$ & $1<1 \mid$ \\
\hline VMO \%MVC (unit: \%) & $26.15 \pm 4.27$ & $26.35 \pm 4.54$ & $25.94 \pm 4.54$ & $29.37 \pm 5.14$ & $26.21 \pm 3.69$ & $32.34 \pm 4.62$ & 9.394 & $0.008^{+}$ & $1<I I \mid$ \\
\hline VMONL (unit: ratio) & $0.73 \pm 0.12: 1$ & $0.74 \pm 0.14: 1$ & $0.74 \pm 0.09: 1$ & $0.83 \pm 0.10: 1$ & $0.73 \pm 0.11: 1$ & $0.92 \pm 0.09: 1$ & 3.657 & $0.042^{*}$ & $\|<\| \|$ \\
\hline
\end{tabular}

Values are present as mean \pm standard deviation.

Q-angle: quadriceps angle, VMO \%MVC: vastus medialis oblique \%maximal voluntary contraction, VMONL: vastus medialis oblique/vastus lateralis. ${ }^{*} p<0.05 ; p<0.01$

\section{2. 그룹 간 안쪽빗넓은근의 근활성도 비교}

그룹 간 중재 전·후 안쪽빗넓은근의 근활성도 비교 결과, 그룹 II와 그룹 III은 그룹 I과 비교하여 \%최대수의적수축에 유의한 차이를 보 였다 $(\mathrm{p}<0.01)$. 사후검정 결과 그룹 $\mathbb{I}$ 은 그룹 I, 그룹 II와비교하여 \% 최대수의적수축의 향상에 효과적이었다(Table 2).

\section{3. 그룹 간 안쪽빗넓은근/가쪽넓은근의 근활성비 비교}

그룹 간 중재 전. 후 안쪽빗넓은근/가쪽넓은근의 근활성비 비교 결 과, 그룹 II와 그룹 $\mathbb{I I}$ 은 그룹 I 과 비교하여 안쪽빗넓은근/가쪽넓은 근의 근활성비에 유의한 차이를 보였다 $(\mathrm{p}<0.05)$. 사후검정 결과 그룹 III은 그룹 I, II와 비교하여 \%안쪽빗넓은근/가쪽넓은근의 근활성비 향상에 효과적이었다(Table 2).

\section{고 찰}

PFPS는 Q-각의 증가와 정강뼈의 과도한 가쪽돌림(exteral rotation)과 결합된 증가된 밖굽이(genu valgus) 스트레스, 목말밑관절의 과도한 엎침과 무릎관절을 안정화 시켜주는 근육 등의 불균형에 의해 발생 되고 무릎벼의 비정상적인 주행(tracking)이 주된 원인이다. ${ }^{22}$ 그 중 넙 다리네갈래근의 가쪽당김에 대한 균형을 유지하는 $\mathrm{VMO}$ 의 약화는 PFPS의 대표적인 원인이며 기능회복을 위해서는 $\mathrm{VMO}$ 의 선택적 강 화와 동원이 강조되고 있으며, ${ }^{23}$ 근력강화를 위한 많은 중재방법 중 근전도-생체되먹임을 이용한 운동방법은 신경계 및 근육뼈대계 질 환의 환자에게 효과적이라고 하였다. ${ }^{24,25}$ 이에 본 연구에서는 PFPS를 보이는 대상자에게 근전도-생체되먹임을 이용한 닫힌 운동학적사슬 운동을 8 주간 중재한 후 Q-각과 넙다리네갈래근의 근활성도에 미치 는 영향을 알아보고자 하였고, 연구결과 운동방법에 따른 그룹 간 중 재 전. 후 $\mathrm{Q}$-각과 넙다리네갈래근의 근활성도에서 유의한 차이를 보 였으며, 사후검정 결과 근전도-생체되먹임을 이용한 닫힌사슬 운동 을 중재한 그룹 $\mathbb{I I}$ 가 Q-각의 감소와 넙다리네갈래근의 근활성도의 증가에 효과적이었다.

Yip과 $\mathrm{Ng}^{26}$ 는 PFPS 진단을 받은 26명을 대상으로 근전도-생체되먹 임을 결합한 운동군과 일반운동군으로 나누어 8 주 동안 중재한 후
넙다리네갈래근의 등속성 근력, 무릎뼈의 미끄러짐과 기울어짐을 비교한 결과 근전도-생체되먹임을 결합한 운동군이 일반운동군과 비교하여 유의한 차이를 보였다. Syme 등 27 은 PFPS를 보이는 69명을 대상으로 근전도-생체되먹임을 통한 선택적인 $\mathrm{VMO}$ 근력강화 운동 군, 일반적인 넙다리네갈래근 근력강화 운동군, 대조군의 세 그룹으 로 나누어 6주 동안 중재한 후 삶의 질과 통증을 비교한 결과 근전도생체되먹임을 통한 선택적인 $\mathrm{VMO}$ 근력강화 운동군이 다른 두 그룹 과 비교하여 통증과 삶의 질에 유의한 차이를 보였다. 본 연구에서도 근전도-생체되먹임을 이용한 닫힌 운동학적 사슬 운동을 중재한 그 룹 III이 그룹 I, II와 비교하여 Q-각과 넙다리네갈래근의 근활성도 에 유의한 차이를 보여 선행연구들을 지지해 주고 있으며, 이와 같은 결과는 PFPS와 같이 안쪽빗넓은근의 약화를 보이는 환자들에게 근 전도-생체되먹임을 이용한 닫힌 운동학적사슬 운동이 필요하다는 것을 뒷받침해 줄수 있다.

Q-각은 무릎손상과 골반, 넙다리, 정강뼈를 포함하는 다리 손상 을 평가하는 데 빈번하게 사용되는 유용한 평가도구이며 비정상적인 $\mathrm{Q}$-각의 증가(남성 $15^{\circ}$, 여성 $20^{\circ}$ 이상)는 무릎뼈의 과운동성과 비정상 적인 정렬 등과 같이 무릎관절의 손상 요인으로 여겨지며 증가된 Q각의 감소는 무릎관절의 기능회복을 의미한다. ${ }^{28}$ Lee 등 ${ }^{29}$ 은 PFPS를 보이는 엘리트 운동선수 34 명을 대상으로 탄력밴드를 이용한 체중지 지운동군, 슬링을 이용한 체중지지운동군, 대조군으로 나누어 8 주 동안 중재한 후 Q-각을 비교한 결과 탄력밴드를 이용한 체중지지 운 동군과 슬링을 이용한 체중지지운동군에서 그룹 내 중재 전. 후 Q각의 유의한 감소를 보였으나 그룹 간 유의한 차이는 없었다. 본 연구 에서는 운동방법에 따른 그룹 간 중재 전·후 Q-각의 비교에서 유의 한 차이를 보였으며, 사후검정 결과 근전도-생체되먹임을 이용한 닫 힌 운동학적사슬 운동을 중재한 그룹 표이 Q-각의 감소에 효과적인 결과를 보여 선행연구와 부분 일치하였다. 반웅크리기 운동과 같은 닫힌 운동학적사슬 운동은 안쪽빗넓은근의 활성을 통해 무릎관절 의 안정성을 제공하여 Q-각이 감소되는 동일한 결과를 보였고, 선행 연구와 다르게 그룹 간 차이를 보인 이유는 근전도-생체되먹임을 통 해 근수축에 대한 실시간 정보의 제공으로 행동수정 및 동기부여를 이끌어 운동단위 동원을 증가시켰으며 닫힌 운동학적사슬 운동과 
의 결합으로 공간적 가중(spatial summation)을 일으켜 더 많은 안쪽 빗넓은근의 활성으로 Q-각의 감소에 차이를 보인 것으로 사료된다.

$\operatorname{Kim}$ 등 18 은 무릎뼈 부정렬 환자 39 명을 대상으로 4주 동안 근전도생체되먹임을 이용한 근력강화 운동군과 테이핑을 적용한 군의 비교 에서 근전도-생체되먹임을 이용한 근력강화 운동군이 안쪽빗넓은근 의 근활성도가 유의하게 증가하였다. $\mathrm{Ng}$ 등 ${ }^{30}$ 은 PFPS 진단을 받은 26 명을 대상으로 근전도-생체되먹임을 결합한 운동군과 일반운동군 으로 나누어 8 주 동안 중재한 후 안쪽빗넓은근과 가쪽넓은근의 근 활성비를 비교한 결과 근전도-생체되먹임을 결합한 운동군이 일반 운동군과 비교하여 유의한 차이를 보였다. 본 연구에서도 근전도-생 체되먹임을 이용한 닫힌 운동학적사슬 운동을 중재한 그룹 피이 다 른 그룹과 비교하여 $\mathrm{VMO}$ 의 근활성도와 $\mathrm{VMO} / \mathrm{VL}$ 근활성비 향상에 효과적인 결과를 보여 선행연구와 동일한 결과를 보였다. 근전도-생 체되먹임을 이용한 닫힌 운동학적사슬 운동은 근수축에 대한 시. 청 각적 되먹임의 제공으로 운동학습과 운동조절의 향상으로 선택적인 $\mathrm{VMO}$ 의 근력강화에 효과적일 것으로 생각된다. 또한 증가된 Q-각은 약화된 $\mathrm{VMO}$ 근력과 상관관계를 보여 선택적인 $\mathrm{VMO}$ 근력강화 운 동은 $\mathrm{VMO} / \mathrm{VL}$ 의 근활성비를 향상시켜 넙다리네갈래근과 무릎힘줄 사이에서 발생되는 가쪽활시위 힘의 감소를 이끌어 Q-각의 감소를 보인 것으로 사료된다.

본 연구는 PFPS를 가진 대상자들에게 운동방법에 따른 Q-각과 넙 다리네갈래근 활성도를 비교하여 근전도-생체되먹임을 이용한 닫힌 운동학적사슬 운동이 Q-각의 감소와 $\mathrm{VMO}$ 의 근활성도 및 $\mathrm{VMO} / \mathrm{VL}$ 근활성비 향상에 효과적임을 증명하였다. 본 연구의 제한점은 특정 지역에서 대상자를 선발하였고 대상자의 수가 적기 때문에 모든 PFPS를 보이는 대상자에게 일반화하기에는 어려움이 있으며, 향후 본 연구를 바탕으로 PFPS를 보이는 대상자에게 근전도-생체되먹임 을 이용한 근력강화 운동이 보행과 삶의 질에 미치는 영향에 대한 추 가적인 연구가 필요할 것으로 사료된다.

\section{Acknowledgements}

The research was has been conducted by the research grant of Sehan university in 2016.

\section{REFERENCES}

1. Nijs J, Van Geel C, Van der auwera C et al. Diagnostic value of five clinical tests in patellofemoral pain syndrome. Man Ther. 2006;11(1):69-77.

2. Welsh C, Hanney WJ, Podschun L et al. Rehabilitation of female dancer with patellofemoral pain syndrome: Applying concepts of regional interdependence in practice. N Am J Sports Phys Ther. 2010;5(2):85-97.
3. Nha KW, Papannagari R, Gill TJ et al. In vivo patellar tracking: clinical motions and patellofemoral indices. J Orthop Res. 2008;26(8):1067-74.

4. Ramappa AJ, Apreleva M, Harrold FR et al. The effects of medialization and anteromedialization of the tibial tubercle on patellofemoral mechanics and kinematics. Am J Sports Med. 2006;34(5):749-56.

5. Kan JH, Heemskerk AM, Ding Z et al. DTI-based muscle fiber tracking of the quadriceps mechanism in lateral patellar dislocation. J Magn Reson Imaging. 2009;29(3):663-70.

6. Freedman BR, Brindle TJ, Sheehan FT. Re-evaluating the functional implications of the Q-angle and its relationships to in-vivo patellofemoral kinematics. Clin Biomech. 2014;29(10):1139-45.

7. Miao P, Xu Y, Pan C et al. Vastus medialis oblique and vastus lateralis activity during a double-leg semi squat with or without hip adduction in patients with patellofemoral pain syndrome. BMC Musculoskelet Discord. 2015;12:289

8. Park S, Lee WJ, Park JW. Differences of onset timing between vastus medialis and lateralis during knee isometric contraction on individuals with genu varum or valgum. J Kor Phys Ther. 2014;26(1):9-14.

9. Park SK, Kang JY. Effects of EMG-Biofeedback training on functional ability and Q-angle in Patellofemoral pain syndrome. J Kor Phys Ther. 2014;26(2):68-73.

10. Dutton RA, Khadavi MJ, Fredericson M. Update on rehabilitation of patellofemoral pain. Curr Sports Med Rep. 2014;13(3):172-8.

11. Fagan V, Delahunt E. Patellofemoral pain syndrome: A review on the associated neuromuscular deficits and current treatment options. Br J Sports Med. 2008;42(10):789-95.

12. Kwon YJ, Park SJ, Jefferson J et al. The effect of open and closed kinetic chain exercises on dynamic balance ability of normal healthy adults. J Phys Ther Sci. 2013;25(6):671-4.

13. Irish SE, Millward AJ, Wride J et al. The effect of closed-kinetic chain exercises and open-kinetic chain exercise on the muscle activity of vastus medialis oblique and vastus lateralis. J Strength Cond Res. 2010; 24(5):1256-62.

14. Yilmaz OO, Senocak O, Sahin E et al. Efficacy of EMG-biofeedback in knee osteoarthritis. Rheumatol Int. 2010;30(7):887-92.

15. Dogan-Aslan M, Nakipoglu-Yuzer GF, Dogan A et al. The effect of eletromyographic biofeedback treatment in improving upper extremity functioning of patients with hemiplegic stroke. J Stroke Cerebrovasc Dis. 2012;21(3):187-92.

16. Park SK, Kim JH. Effects of EMG-biofeedback training on total knee replacement patient's lower extremity muscle activity and balance. J Kor Phys Ther. 2013;25(2):81-7.

17. Oravitan M, Avram C. The effectiveness of electromyographic biofeedback as part of a meniscal repair rehabilitation programme. J Sports Sci Med. 2013;12(3):526-32.

18. Kim DY, Kim SH, Lim YE et al. Effect of EMG Biofeedback training and taping on vastus medialis oblique for functional improvement of patient with patella malalignment. J Kor Phys Ther. 2008;20(3):35-44.

19. Coqueiro KR, Bevilaqua-Grossi D, Berzin F et al. Analysis on the activation of the VMO and VL muscles during semisquat exercise with and without hip adduction in individuals with patellofemoral pain syndrome. J Electromyogr Kinesiol. 2005;15(6):596-603.

20. Yang DJ, Uhm YH, Kim JH. The biofeedback scapular stabilization exercise in stroke patients effect of muscle activity and function of the upper 
extremity. J Kor Phys Ther. 2015;27(5):325-31.

21. Park SK, Yang DJ, Park JM et al. Analysis of patellar tracking and Q-angle during semi-squat exercises. Kor J Sport Biomechanics. 2011;21(1):10714.

22. Petersen W, Ellermann A, Gosele-Koppenburg A et al. Patellofemoral pain syndrome. Knee Surg Sport Traumatol Arthrosc. 2014;22(10):226474.

23. Pattyn E, Verdonk P, Steyaert A et al. Vastus medialis obliques atrophy: Does it exist in patellofemoral pain syndrome?. Am J Sports Med. 2011;39(7):1450-5.

24. Kim YK, Song JC, Choi JW et al. Functional electric stimulation-assisted biofeedback therapy system for chronic hemiplegic upper extremity function. J Kor Phys Ther. 2012;24(6):409-13.

25. Koh EK, Weon JH, Jung DY. Effects of activation of gluteus maximus and abdominal muscle using EMG Biofeedback on lumbosacral and tibiocalcaneal angles in standing position. J Kor Phys Ther. 2013; 25(6):411-6.
26. Yip SL, Ng GY. Biofeedback supplementation to physiotherapy exercise programme for rehabilitation of patellofemoral pain syndrome: A randomized controlled pilot study. Clin Rehabil. 2006;20(12):1050-7

27. Syme G, Rowe P, Martin D et al. Disability in patients with chronic patellofemoral pain syndrome: a randomised controlled trial of VMO selective training versus general quadriceps strengthening. Man There. 2009;14(3):252-63.

28. Freedman BR, Yoon K. Physical examination and patellofemoral pain syndrome. Am J Phys Med Rehabil. 2006;85(3):234-43.

29. Lee J, Lee H, Lee W. Effect of weight-bearing therapeutic exercise on the Q-angle and muscle activity onset times of elite athletes with patellofemoral pain syndrome: A randomized controlled trial. J Phys Ther Sci. 2014;26(7):961-4.

30. Ng GY, Zhang AQ, Li CK. Biofeedback exercise improved the EMG activity ratio of the medial and lateral vast muscles in subjects with patellofemoral pain syndrome. J Electromyogr Kinesiol. 2008;18(1):128-33. 